\title{
Implicações do trabalho remoto em uma empresa de base tecnológica
}

\section{Implications of remote work in a technology-based company}

\author{
Ana Luiza Leite Mestranda em Administração. Universidade do Estado de Santa Catarina (UDESC) - Brasil. \\ anaetiel@yahoo.com.br \\ Taiana Beatriz Junkes da Silveira Mestranda em Administração. Universidade do Estado de Santa Catarina (UDESC) - Brasil. \\ taijunkes@gmail.com. \\ Dannyela da Cunha Lemos Doutora em Administração. Universidade Federal de Santa Catarina (UFSC) - Brasil. \\ lemosda@gmail.com
}

\section{RESUMO}

Esse trabalho objetivou avaliar as implicações do trabalho remoto em uma equipe de desenvolvedores de software de uma empresa de base tecnológica (EBT) na cidade de Florianópolis. Os dados coletados advêm de um questionário disponibilizado pelo Google Forms e respondido, entre 28/10/2019 e 04/11/2019, por nove colaboradores que trabalham remotamente em tempo integral, constando 45 perguntas (quatro discursivas e 41 de múltipla escolha). Também foi realizada uma entrevista com o gestor da equipe, presencialmente, com um roteiro semiestruturado (sete questões discursivas) em 19/11/2019. Verificaram-se o perfil dos respondentes, suas motivações e personalidade. Também foi investigada a modalidade de trabalho remoto exercida, caracterizada por home office e trabalho realizado durante os dias úteis. Analisou-se o modo como funciona o trabalho remoto na organização no que se refere a controle de resultados, informações sobre a modalidade e comunicação. Por último, apresentaram-se as mais diversas vantagens agregadas a essa forma laboral, e os inúmeros desafios à organização e aos colaboradores.

Palavras-chave: Trabalho Remoto. Teletrabalho. Gestão de Pessoas. Empresa de Base Tecnológica - EBT.

\section{ABSTRACT}

This paper aims to evaluate the implications of remote work in a team of software developers of a technologybased company $(\mathrm{TBC})$ in the city of Florianópolis. The data collected comes from a questionnaire made available by Google Forms and answered, between 10/28/2019 and 11/04/2019, by nine employees who work remotely full time, with 45 questions (four discursive and 41 multiple choice). An interview with the team manager was also carried out, in person, with a semi-structured script (seven discursive questions) on $11 / 19 / 2019$. Respondents' profile, motivations and personality were verified. The modality of remote work exercised, characterized by home office and work performed during working days, was also investigated. An analysis of how remote work in the organization works regarding control of results, information about the modality and communication was analyzed. Finally, the most diverse advantages added to this form of work and the number of challenges to the organization and employees were presented.

Keywords: Remote Work. Teleworking. People management. Technology Based Company - TBC. 


\section{INTRODUÇÃO}

A crescente utilização das tecnologias de informação e comunicação (TIC) tem possibilitado a realização do trabalho em qualquer lugar (ROCHA; AMADOR, 2018). O trabalho, então, tem sido realizado a distância por diferentes motivos e com diversas ferramentas. $O$ trabalho remoto é um conjunto de situações em que os colaboradores podem trabalhar ou não na sede da empresa com ou sem utilização de tecnologias da informação e comunicação (NOGUEIRA; PATINI, 2012).

Na pesquisa Human Capital Trends (DELLOITE, 2018) verifica-se que o segundo programa de gestão de pessoas mais valorizado é o teletrabalho com $70 \%$, enquanto apenas $27 \%$ dos empregadores oferecem essa modalidade de trabalho (DELLOITE, 2018). As empresas que adotam flexibilidade no trabalho têm uma enorme vantagem competitiva em relação à produtividade e à retenção, entretanto, é verificado um novo conjunto de desafios: dificuldades na colaboração e vínculo (LINKEDIN, 2019).

As empresas de base tecnológica (EBT), por sua vez, que se destacam pela incorporação de inovações tecnológicas no desenvolvimento de produtos, têm gerado grande interesse para diversos atores no mercado. Sua importância como espaço de atuação profissional é reconhecida por engenheiros e cientistas há muito tempo, os quais têm pesquisado sobre as especificidades de tais empresas (CÔRTES et al., 2005). As EBT podem ser entendidas como uma classificação de empresas, que surgem para distinguir as empresas em relação às bases subjacentes como o conhecimento e a tecnologia (PESCIO; PETRASIC, 2016). As EBTs têm enfrentado problemas que dificultam as iniciativas de inovação como: a falta de fundos e mecanismos de financiamento, uma infraestrutura adequada de acesso a fontes de conhecimento, maturidade legal, estabilidade macroeconômica, apoio governamental, disponibilidade de mão de obra educada e qualificada, bem como resistências organizacionais para inovar (MELO et al., 2015).

Nesta esteira, encontra-se uma empresa de base tecnológica, que faz o uso de trabalho remoto como alternativa a retenção e atração de colaboradores especificamente qualificados, em um contexto de mercado que tem enfrentado a concorrência por este tipo de mão de obra. Objetivou-se, então, avaliar as implicações do trabalho remoto de uma equipe de desenvolvedores de software de uma empresa de base tecnológica na cidade de Florianópolis a fim de esclarecer como tem sido a experiência nesse tipo de empresa e quais as diferenças encontradas de acordo com estudos sobre o tema. Inicialmente, apresentam-se estudos acerca do tema e os procedimentos metodológicos utilizados para a realização da pesquisa. Por fim, são identificados os resultados encontrados e as considerações finais observadas.

\section{FUNDAMENTAÇÃO TEÓRICA}

A fundamentação teórica está dividida em quatro tópicos abordados pela literatura na pesquisa sobre a temática do trabalho remoto. Inicialmente apresentam-se características relacionadas ao perfil de colaboradores que buscam o trabalho remoto. Na sequência descrevem-se aspectos do ambiente $\mathrm{e}$ periodicidade do trabalho remoto, bem como questões relacionadas a seu funcionamento. Por último, são apresentados os impactos do trabalho remoto.

\subsection{Ambiente e periodicidade do trabalho remoto}

O trabalho remoto inclui vários modos de trabalho a distância com ou sem uso de tecnologias. Desta forma, é necessário que seja definido o local de trabalho (SILVA, 2014), pois verificam-se as seguintes distinções: (i) Home office (AGUILERA et al., 2016): trata da peculiaridade de ser realizado na casa do trabalhador; (ii) Escritórios satélites: extensões atomizadas da empresa central (TREMBLAY, 2002); (iii) Telecentros, coworkings: estabelecimentos próximos à moradia dos trabalhadores que suportam postos de trabalho de empregados de uma ou várias organizações (TREMBLAY, 2002); (iv) Trabalho móvel: trabalho longe do principal centro de trabalho e da moradia, por meio de viagens de negócios, trabalho de campo ou em instalações do cliente (ROSENFIELD; ALVES, 2011). 
No que tange ao ambiente de trabalho, seja onde for, deve ter aspectos que permitam a realização do trabalho com segurança e conforto. Deve ser um ambiente calmo, onde não há interrupções de pessoas familiares, ter mesa e cadeira de maneira ergonômica, ter a mesa de trabalho organizada, boa luminosidade e limpeza adequada (SILVA, 2004). Além disso, a organização deve instruir os colaboradores que irão realizar o trabalho remoto, principalmente no que tange às medidas para evitar futuras doenças e acidentes de trabalho (BRASIL, 2017). Apresenta-se como alternativa a Gestão de Qualidade de Vida no Trabalho para melhoria das condições do ambiente em que os colaboradores desempenham suas tarefas (SILVA, 2004).

Em relação ao tempo e periodicidade de trabalho remoto, podem ser: (i) parcialmente (AGUILERA et al., 2016), por meio de algumas horas do dia ou alguns dias da semana e (ii) totalmente, todos os dias em teletrabalho. $O$ horário em que se trabalha também é algo a se verificar, já que pode ocorrer melhor produtividade sentida em diferentes horários (HILL; FERRIS; MÄRTINSON, 2003). Ainda, a percepção dos colaboradores em relação ao tempo trabalhado remotamente pode ser verificada. Maruyama, Hopkinson e James (2009) verificaram que a maioria dos colaboradores em trabalho remoto perceberam uma jornada de trabalho maior do que a padrão.

\subsection{Perfil do trabalhador remoto}

Os estudos empíricos sobre o tema normalmente traçam os perfis sobre o trabalhador remoto. Por exemplo, Hau e Todescat (2018), em sua análise de uma organização pública, verificaram que a maioria dos teletrabalhadores era casado, do sexo feminino e tinha filhos. Referente a motivação para realizar o trabalho a distância foram citados: relação familiar, deslocamento e flexibilidade (HAU; TODESCAT, 2018). Nilles (1988) corrobora esses achados ao afirmar que a propensão ao trabalho remoto é proporcional ao tempo de deslocamento trabalho-casa.

Sullivan e Lewis (2001) enquadram a motivação para o teletrabalho em dois grupos: razões domésticas e familiares e razões laborais e individuais. No que tange a razões domésticas e familiares, percebese a motivação em trabalhar remotamente pelo fato de: ter filhos, ser casado, estar grávida e/ou buscar maior relacionamento familiar (HAU, TODESCAT, 2018). No que tange a razões laborais e individuais, verifica-se a motivação em busca de autonomia no trabalho (HILL; FERRIS; MÄRTINSON, 2003), redução de deslocamento e flexibilidade (HAU; TODESCAT, 2018).

Também é importante as organizações estabelecerem mecanismos para avaliar como são as condições de vida do colaborador antes de incluí-lo na modalidade de teletrabalho. Visto que o trabalho remoto tem a característica de ocasionar melhor equilíbrio entre trabalho e família (ILLEGEMS; VERBEKE; S'JEGERS, 2001) deve-se buscar informações acerca da responsabilidade do colaborador em casa. Essas informações são importantes, pois se o colaborador tem responsabilidades maiores em casa, a organização e o colaborador devem definir juntos possíveis estratégias para prevenir a interferência da família no trabalho (SOLÍS, 2017).

Ainda, referente ao perfil do colaborador, há certas características que são necessárias para o trabalho remoto. Pinto (2003) elenca oito atributos pessoais e suas respectivas definições, que devem ser analisados em potenciais teletrabalhadores: (i) Automotivação: demonstração de interesse e entusiasmo capazes de contagiar os colegas; (ii) Autodisciplina: capacidade de controlar-se a si próprio, de impor-se um comportamento apropriado; (iii) Confiança: crença nas próprias qualidades e na potencialidade de resolver problemas com eficácia; (iv) Flexibilidade: capacidade de adequar-se às novas circunstâncias e abertura a novos conhecimentos; (v) Independência: capacidade de tomar decisões por conta própria, responsavelmente; (vi) Bom senso: demonstração de equilíbrio nas suas colocações, nas emoções e nas atitudes; (vii) Confiabilidade: capacidade de despertar a confiança de outrem pela ponderação de suas colocações e atitudes; (viii) Adaptabilidade: capacidade de ajustar-se a qualquer ambiente sem problemas. 


\subsection{Funcionamento do trabalho remoto}

As experiências podem ser analisadas antes e depois do trabalho remoto considerando a satisfação profissional, a qualidade de vida e o desempenho das tarefas. São aspectos importantes de serem medidos, pois apresentam mudanças estabelecidas pela alteração de modelo de trabalho (SILVA, 2004).

Outro ponto a ser analisado no trabalho remoto são as interações profissionais, com colegas de trabalho e gestor (SILVA, 2004). Collins, Hislop e Cartwright (2016) verificaram que embora os trabalhadores remotos nem sempre abordaram supervisores para ajudar, preferindo consultar outros teletrabalhadores, pouco mais da metade dos trabalhadores remotos tiveram uma relação mais pessoal com o líder de equipe, que fornece, até mesmo, apoio emocional. Em relação aos colegas de trabalhadores remoto, estes precisam entender as necessidades do colaborador remoto e buscar a melhor maneira de se comunicar com eles (KATZ, 1987). O trabalho remoto tem o potencial para melhorar a comunicação entre o colaborador e o gestor, como também a comunicação lateral com o colega de trabalho (DUXBURY; NEUFELD, 1999).

O trabalho remoto tem introduzido novas formas de controle. O controle por resultados ou objetivos sugere que a possibilidade reduzida de monitorar o comportamento dos colaboradores pode ser compensada por uma ênfase crescente nos controles de saída (GROEN et al., 2018). Mross (2016) acredita que a análise do desempenho do teletrabalhador deve ser objetiva, baseada exclusivamente no resultado da tarefa, considerando o prazo de execução e a qualidade do trabalho. A confiança que se credita no colaborador remoto se torna peça- chave para que eles possam agir com flexibilidade enquanto trabalham, o que pode levar a níveis mais altos de proatividade e adaptabilidade a mudanças (SOLÍS, 2017). Em relação à produtividade, existem alegações contraditórias entre os colaboradores remotos e a literatura acadêmica até o momento não oferece respostas satisfatórias (DUTCHER, 2012). Mross (2016) verificou que há organizações que solicitam aumento de produtividade aos trabalhadores remotos, enquanto outras não.

Assim como há preocupação com o perfil dos colaboradores em trabalho remoto, há a necessidade de se estabelecer quais atividades são possíveis de serem realizadas à distância. A relação de atividades não deve ser demasiadamente detalhista a ponto de engessar o estabelecimento das tarefas, tampouco deve ser genérica demais, que permita a inclusão de tarefas não passíveis de mensuração objetiva em termos de prazos e qualidade (MROSS, 2016).

\subsection{Impactos da realização do trabalho remoto}

A literatura tem disposto impactos positivos e negativos com a aplicação do trabalho remoto (LEITE; LEMOS; SCHEINDER, 2019). A experiência do trabalho remoto pode alterar sensações como: ansiedade, depressão, desamparo, desespero, irritação, mau humor, cansaço e dor (física). Silva (2004) verificou que a realização do trabalho remotamente trouxe maior ansiedade aos participantes, por exemplo.

No que se refere aos benefícios para os colaboradores em nível pessoal são citados: (i) qualidade de vida em família; (ii) organização do tempo livre; (iii) menos estresse com trânsito e (iv) redução de gastos com alimentação, vestuário e deslocamento (HAU; TODESCAT, 2018). Benefícios em nível profissional: (i) melhora em competências individuais: agilidade, proatividade e responsabilidade (ADERALDO; ADERALDO; LIMA, 2017); (ii) maior concentração; (iii) flexibilidade (HAU; TODESCAT, 2018); (iv) aumento de satisfação do trabalho (ABDULLAH; ISMAIL, 2012); (v) menor número de interrupções (TREMBLAY; THOMSIN, 2012), e (vi) aumento da produtividade (ILLEGEMS; VERBEKE, 2004). Em relação aos benefícios para a organização apresentam-se: (i) aumento de produtividade; (ii) diminuição de absenteísmo e rotatividade; (iii) maior amplitude no recrutamento de pessoas; (iv) maior motivação e (v) redução de custos com infraestrutura (HAU; TODESCAT, 2018).

No que tange aos impactos negativos aos colaboradores que exercem o trabalho remoto são verificados em nível pessoal: (i) isolamento social; (ii) transferência dos custos (HAU; TODESCAT, 2018); (iii) distração com família e atividades domésticas (HAZAN; MORATO, 2018) e (iv) redução da interação pessoal presencial (ILLEGEMS; VERBEKE, 2004). Em nível profissional há: (i) dificuldade de participação em geração de ideias e discussões (TUNG; TURBAN, 1996); (ii) redução da interação profissional (HAU; TODESCAT, 2018); (iii) 
aumento de pressão (TREMBLAY; THOMSIN, 2012); (iv) perda de espírito de equipe (TREMBLAY; THOMSIN, 2012) e (v) redução da possibilidade de promoção (HAU; TODESCAT, 2018).

À organização são verificadas desvantagens como: (i) vulnerabilidade de dados e (ii) contratos diversificados de trabalho para administrar (HAU; TODESCAT, 2018). Observa-se que a segurança de dados, privacidade e confidencialidade não pode ser negligenciada quando o trabalho é realizado em casa (TUNG; TURBAN, 1996), sendo um ponto a ser analisado pela organização antes de implementar essa modalidade laboral.

\section{PROCEDIMENTOS METODOLÓGICOS}

A pesquisa foi realizada em uma empresa de base tecnológica, sediada na capital do estado de Santa Catarina - Florianópolis, que tem se consolidado, no cenário nacional e internacional, como polo tecnológico e de inovação (BBC News, 2009; PMF). De acordo com a PMF, o desenvolvimento dessa atividade econômica é destaque na economia do município, tornando-se um importante componente para o desenvolvimento local. A cidade conta com incubadoras - CELTA e MIDI Tecnológico, parques tecnológicos - Alpha e Sapiens Parque e quatro universidades, que tem contribuição direta sobre o reconhecimento no que diz respeito a essa atividade econômica e para a formação de profissionais altamente qualificados.

A empresa estudada tem quase 3 décadas de atuação no desenvolvimento de software para organizações públicas e privadas. Atualmente conta com cerca de 1900 colaboradores, sendo que aproximadamente 140 trabalham diretamente na unidade de negócio que atende organizações privadas, a qual se refere este estudo. A unidade atua no desenvolvimento e comercialização de uma plataforma especialista em gestão de empresas da construção civil e dentre os desafios enfrentados nos últimos três anos, destaca-se a dificuldade na contratação de profissionais voltados ao desenvolvimento de software.

Os profissionais dessa unidade de negócio estão divididos em três grandes equipes: Operações, Tecnologia e Ecossistema, conforme demonstra a Figura 1.

Figura 1 - Organograma consolidado da unidade de negócio

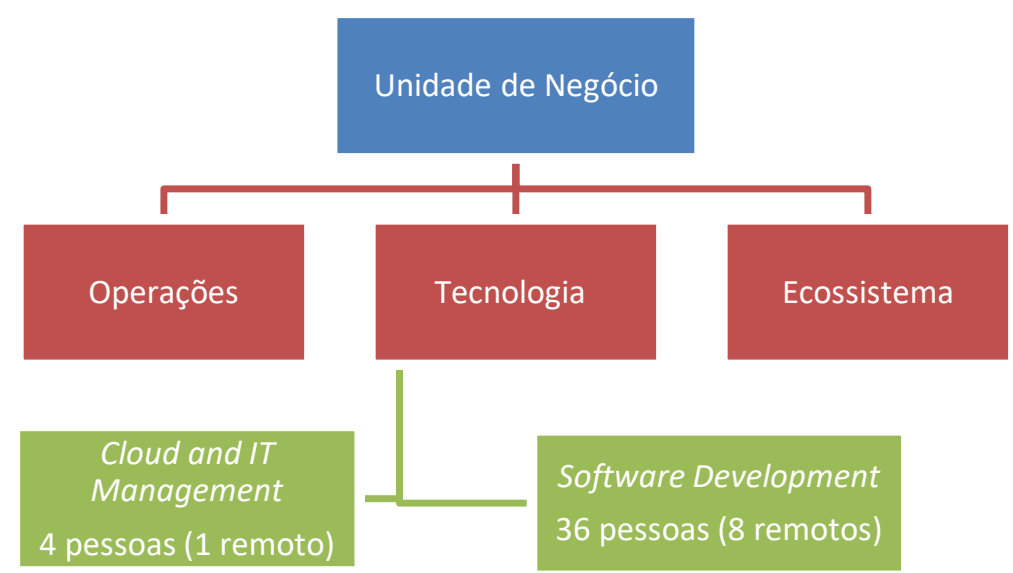

Fonte: produção própria (2019).

Por atuar com o desenvolvimento de software, uma das principais necessidades, no que diz respeito a composição do seu corpo de trabalho, é de profissionais voltados à área técnica, especificamente para o desenvolvimento de seu produto. $\mathrm{E}$, nos últimos 3 anos, frente a maior valorização destes profissionais no 
mercado mundial, a empresa tem enfrentado dificuldades para reter e, principalmente, contratar novos. Uma das alternativas para que a Unidade de Negócio em questão continuasse em pleno crescimento, foi aderir, em 2018, ao trabalho remoto e às políticas de contratação a ele relacionadas. Desta forma, a área de "Tecnologia" atualmente conta com 9 colaboradores atuando na modalidade de trabalho remoto de forma integral. Além disso, os demais colaboradores podem ajustar com o gestor flexibilidade de trabalho ou até mesmo trabalho remoto parcial.

A presente pesquisa se caracteriza com abordagem qualiquantitativa. A coleta de dados foi estabelecida por meio de dois públicos: entrevista ao gestor realizada em 19/11/2019 presencialmente, e questionário, desenvolvido no Google Forms, enviado aos nove teletrabalhadores, respondido entre 28/10/2019 e 04/11/2019. O questionário (45 questões, sendo 4 discursivas e o restante de múltipla escolha) e roteiro de entrevista (sete questões discursivas) foram desenvolvidos com base nos questionários aplicados por Hau e Todescat (2018), Silva (2004) e Pinto (2003), além de aspectos críticos em relação ao tema encontrados na literatura. No primeiro bloco de perguntas do questionário foram solicitados dados básicos em relação ao perfil (HAU; TODESCAT, 2018) e atributos pessoais (PINTO, 2003), nos quais os colaboradores avaliaram diversas sentenças relacionadas por meio de uma escala de 1 (discordo totalmente) a 5 (concordo totalmente). No segundo bloco são questionados sobre o ambiente da empresa e o atual ambiente de trabalho remoto (SILVA, 2004), assim como onde exercem as atividades e em quais períodos. No terceiro bloco, são questionados sobre a interação com colegas e chefia (DUXBURY; NEUFELD, 1999), controle de resultados (GROEN et al., 2018) e utilização das TICs (TUNG; TURBAN, 1996). No quarto bloco, são questionados sobre a satisfação profissional e qualidade de vida antes e depois do trabalho remoto (HAU; TODESCAT, 2018), sensações que sentem antes e depois do trabalho remoto (SILVA, 2004) e os benefícios e dificuldades encontrados pelos trabalhadores remotos. A entrevista realizada com o gestor foi semiestruturada, e teve como intuito identificar os objetivos da empresa com a adoção do trabalho remoto, o acompanhamento do trabalho e das jornadas dos trabalhadores remotos, da qualidade do seu trabalho, a percepção de aumento de eficiência e produtividade, facilidades e dificuldades observadas com relação aos colaboradores que trabalham a distância.

Para a análise dos dados verifica-se a utilização de análise de conteúdo categorial (BARDIN, 2004), onde utiliza-se procedimentos sistemáticos e objetivos de descrição do conteúdo das entrevistas e questionários por meio de categorizações que permitam a inferência de conhecimentos relativos às condições das variáveis identificadas. Ainda, para as questões fechadas do questionário, utilizou como análise de dados estatística descritiva por meio do software Excel. As categorias analisadas foram: perfil do trabalhador remoto, ambiente e periodicidade do trabalho remoto, funcionamento do trabalho remoto e os impactos da realização do trabalho remoto.

Em relação ao perfil dos respondentes, observa-se que todos estão inseridos na faixa etária de 26 a 45 anos, sendo 2 solteiros e 7 casados. Todos são do sexo masculino, 5 graduados e 4 pós-graduados em áreas de formação ligadas à tecnologia: ciências da computação, sistemas da informação, análise e desenvolvimento de sistemas. Apenas um colaborador reside a menos de $30 \mathrm{~km}$ da empresa, os demais residem há mais de 50 km: residentes em Palhoça, Tubarão, Porto Alegre e Foz do Iguaçu. Em relação ao tempo de trabalho no cargo, 6 colaboradores estão há mais de 5 anos, enquanto 3 estão entre menos de 1 ano e 3 anos. Percebe-se que o tempo em trabalho remoto também é, de certa forma, recente: 4 colaboradores estão nessa modalidade há menos de um ano e 5 colaboradores há mais de 1 ano e menos que 3 anos. A ida presencialmente à empresa é feita com pouca frequência: em média de 3 a 4 vezes por ano.

Caracterizado os respondentes, destaca-se que estes colaboradores exercem o trabalho remoto em tempo integral e têm como local de trabalho a própria residência ou de parentes (AGUILERA et al., 2016), sendo que dois mesclam essa localização com coworking (TREMBLAY, 2002). Por fim, informa-se que todos fazem parte da EBT analisada, ou seja, o trabalho é assalariado por uma organização (TREMBLAY, 2002).

\section{RESULTADOS}


Nesta seção são apresentadas informações sobre os perfis dos trabalhadores remotos investigados, como também aspectos sobre o ambiente, a periodicidade e o funcionamento dessa nova forma laboral na organização. Por fim, identificamos os impactos, tanto positivos quanto negativos, da realização do trabalho remoto aos funcionários.

\subsection{Perfil do trabalhador Remoto}

Observou-se que apenas uma pessoa prefere trabalhar sozinha e outras duas preferem trabalhar em equipe. Para as demais o trabalho individual ou em equipe é indiferente. Nota-se que nem sempre o trabalho remoto é escolhido devido a sua forma de trabalho, mas como alternativa para o momento da vida em que o colaborador está passando.

A maioria dos colaboradores percebe oportunidades de crescimento na empresa, mesmo trabalhando remotamente, contrariando com os achados da pesquisa de Hau e Todescat (2018). Quatro colaboradores afirmaram que têm facilidade de realizar várias tarefas ao mesmo tempo, três colaboradores não têm facilidade e outros dois mantiveram uma posição neutra. Isso pode ter acontecido em razão de a empresa trabalhar com o uso de metodologias ágeis, onde se busca não trabalhar em várias tarefas ao mesmo tempo.

A maioria dos colaboradores afirmam que são autodisciplinados, automotivados, têm facilidade de iniciar novas atividades e têm facilidade de concentração, características favoráveis a realização de trabalho remoto (PINTO, 2003). Todos afirmam que conseguem administrar as relações familiares e profissionais no mesmo espaço em que vivem e trabalham, o que se torna importante nessa modalidade de trabalho, ocasionando melhor equilíbrio entre trabalho e família (ILLEGEMS; VERBEKE; S'JEGERS, 2001).

Os motivadores do trabalho remoto podem ser classificados entre família, custo de vida e qualidade de vida por não precisar se deslocar até o trabalho. Confirma-se então, que a propensão ao trabalho remoto é proporcional ao tempo de deslocamento trabalho-casa (NILLES, 1988). Os motivadores citados compreendem questões pessoais e não necessariamente pela identificação de se trabalhar a distância.

\subsection{Ambiente e periodicidade do trabalho remoto}

Todos os trabalhadores remotos percebem o ambiente de trabalho remoto como melhor ou igual ao ambiente de trabalho na sede da empresa (antes do trabalho remoto). Também foram avaliados de forma positiva os aspectos do ambiente de trabalho remoto, afirmando que não há interrupções de pessoas familiares, o local de trabalho tem mesa e cadeira de maneira ergonômica, mesa de trabalho organizada, boa luminosidade e limpeza adequada. Silva (2004) apresenta esses elementos analisados antes e depois do teletrabalho com grande ênfase para que haja a continuidade do bem-estar do colaborador. Além disso, sete colaboradores afirmaram que não há responsabilidade de cuidar de outras pessoas enquanto trabalha (SOLís, 2017). Contudo, percebe-se que apenas quatro colaboradores informam que trabalham em um ambiente sem ruídos.

Destaca-se que estes colaboradores exercem o trabalho remoto em tempo integral e têm como local de trabalho a própria residência ou de parentes (AGUILERA et al., 2016), sendo que dois mesclam essa localização com coworking (TREMBLAY, 2002).

Além da localização, torna-se importante ter a ciência sobre o tempo de trabalho remoto. A maioria dos colaboradores afirmou que realiza o trabalho remoto nos períodos comerciais: matutino e vespertino. Porém houve trabalhadores que afirmaram trabalhar a noite e durante a madrugada. Isso ocorre devido a melhor produtividade sentida em diferentes horários (HILL; FERRIS; MÄRTINSON, 2003). No que diz respeito aos dias da semana em que realizam o trabalho remoto, todos os trabalhadores concentram seu trabalho em dias úteis, sendo que nem todos trabalham remotamente nas segundas e sextas-feiras. Infere-se que os colaboradores têm tido uma boa gestão de tempo para não deixar trabalho para o final de semana, como ainda, conseguem fazer uma jornada mais condensada durante a semana prolongando o final de semana como observado em um caso. A percepção dos colaboradores em relação ao tempo trabalhado remotamente 
é vista pela maioria dos colaboradores como uma jornada de trabalho maior do que a padrão, o mesmo identificado por Maruyama, Hopkinson e James (2009).

\subsection{Funcionamento do trabalho remoto}

Dentre os pesquisados, um afirmou não conhecer as orientações de segurança dos dados solicitadas pela organização. Verifica-se que a segurança de dados é de grande importância para a empresa. Mesmo que apenas um não tenha o conhecimento sobre essas orientações, torna-se importante intensificá-las e divulgar ainda mais as práticas de segurança dos dados. Afinal, a segurança de dados, privacidade e confidencialidade não pode ser negligenciada quando o trabalho é realizado em casa (TUNG; TURBAN, 1996). Todos os pesquisados afirmaram ter dispositivos e conexão adequados ao trabalho remoto, não sendo reportados problemas com as tecnologias da informação e comunicação utilizadas.

A maioria dos pesquisados afirmou que a interação com os colegas da equipe de trabalho é a mesma (2) ou maior (5) que anteriormente, confirmando a contínua comunicação com os colegas de trabalho (KATZ, 1987). Apenas dois colaboradores relataram ser mais baixa do que antes do trabalho remoto. Já, no que diz respeito a interação com colegas de outras equipes, a maioria afirmou que é menor que anteriormente (7), enquanto o restante afirmou que a interação continua a mesma. Por um lado, percebe-se que há um aumento na comunicação entre a equipe, e por outro, o colaborador remoto acaba perdendo contato com as demais equipes.

Quando questionados sobre a comprovação do trabalho remoto, os colaboradores afirmaram que ela ocorre por meio da entrega de resultados (GROEN et al., 2018). Existem acordos e interações constantes com o time que suportam esta comprovação, tudo isso com uma relação de confiança entre os membros das equipes (SOLÍS, 2017). Segundo um dos colaboradores "[...] é uma relação muito baseada na confiança, e acho isso positivo. A minha comprovação de estar trabalhando se dá através da entrega das minhas atividades dentro dos limites de prazo acordados com o meu time".

No que diz respeito à gestão, não há um acompanhamento próximo do trabalho e a jornada de trabalho dos colaboradores em regime remoto. Segundo o gestor as equipes têm autonomia para fazer o acompanhamento, pois são "autogerenciáveis". E ainda, o profissional "não tem mais prestação de contas, não bate ponto, não tem hora extra e nem banco".

\subsection{Impactos da realização do trabalho remoto}

A qualidade de vida geralmente é notada pela permissão em gerir seu tempo e se beneficiar na dispensa do deslocamento (HAU; TODESCAT, 2002). Observou-se que a maioria dos colaboradores (8) percebeu uma melhora na qualidade de vida depois de aderir ao trabalho remoto. Apenas um colaborador não sentiu essa melhora. Do mesmo modo, para a maioria (7), houve um aumento na satisfação profissional dos colaboradores que aderiram ao trabalho remoto (ABDULLAH; ISMAIL, 2012). Dois colaboradores mantiveram a satisfação profissional em relação ao trabalho presencial.

No que se refere às sensações do colaborador, observa-se que alguns sentimentos como irritação, mau humor, cansaço e dor física, que ocorriam eventualmente ou sempre, passaram a ocorrer para menos colaboradores e de forma eventual no trabalho remoto. Os Gráficos 1 e 2, a seguir, apresentam as sensações antes de realizar o trabalho remoto e depois. 
Gráfico 1 - Sensações antes do trabalho remoto

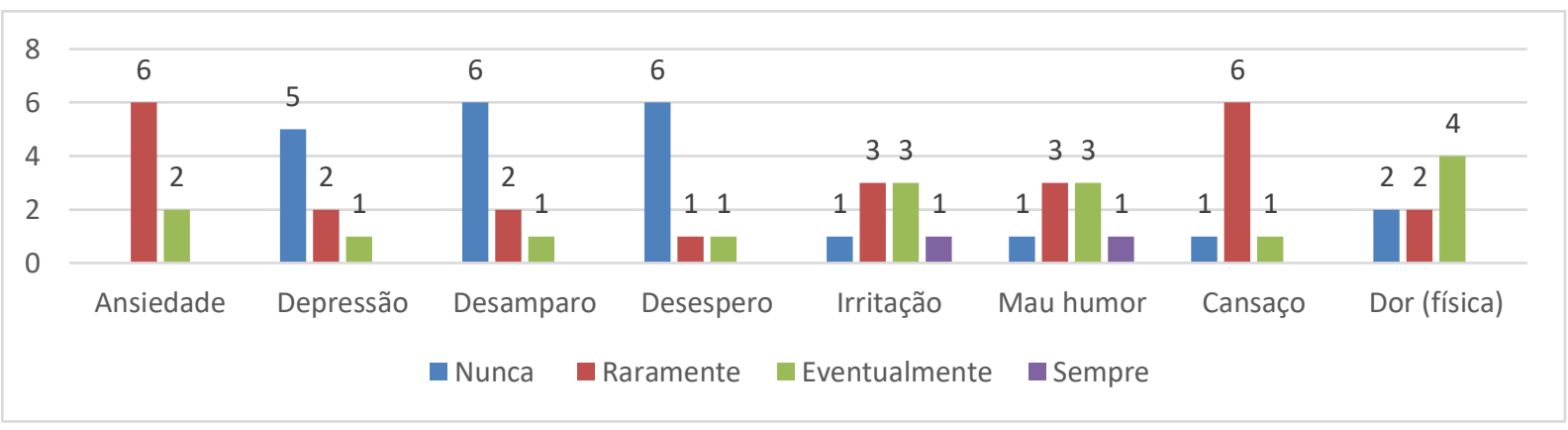

Fonte: produção própria (2019).

Gráfico 2 - Sensações a partir do trabalho remoto

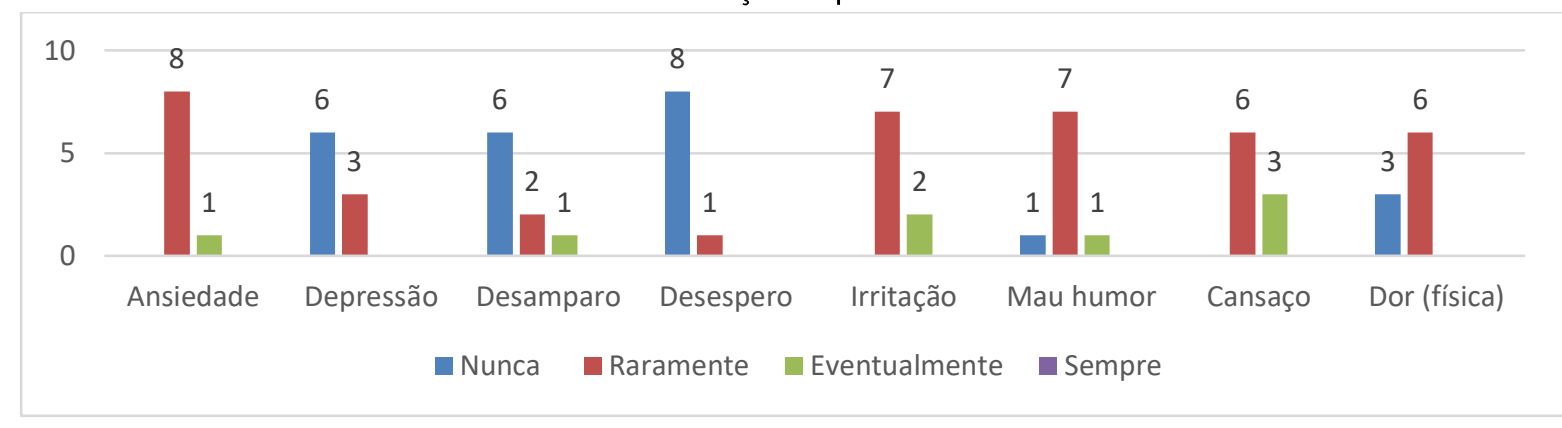

Fonte: produção própria (2019).

Comparando os gráficos, percebe-se que o trabalho remoto pode ter ajudado a reduzir a frequência das diversas sensações negativas: ansiedade, depressão, desespero, irritação, mau humor, cansaço, dor física. Apenas o item desamparo manteve-se igualmente nas duas ocasiões. Reduz, até mesmo a ansiedade, contrariando os achados de Silva (2004). Este, pode ser melhorado por meio de práticas de assistência e atenção de colaboradores presenciais aos colaboradores remotos.

Dentre os colaboradores há a percepção de que a organização não transmite orientações de saúde e ergonomia referente ao trabalho remoto (5), não transmite orientações psicológicas referente ao trabalho remoto (8) não desenvolve cursos úteis para a realização do trabalho remoto (gestão do tempo, desenvolvimento de disciplina, comunicação à distância etc.) (8). Sugere-se então, o desenvolvimento de práticas e orientações sobre esses temas, sendo possível melhorar, por consequência, o item desamparo sentido pelos colaboradores remotos. A organização deve instruir os colaboradores que irão realizar o trabalho remoto, principalmente no que tange às medidas para evitar futuras doenças e acidentes de trabalho (BRASIL, 2017).

No que diz respeito aos benefícios profissionais percebidos pelos colaboradores, destacam-se, principalmente: maior concentração; diminuição de estresse com deslocamento (HAU; TODESCAT, 2018); menor número de interrupções (TREMBLAY; THOMSIN, 2012); e aumento de produtividade (ILLEGEMS; VERBEKE, 2004) (Gráfico 3). Ao todo, nove benefícios profissionais foram citados. 


\section{Gráfico 3 - Benefícios profissionais percebidos}

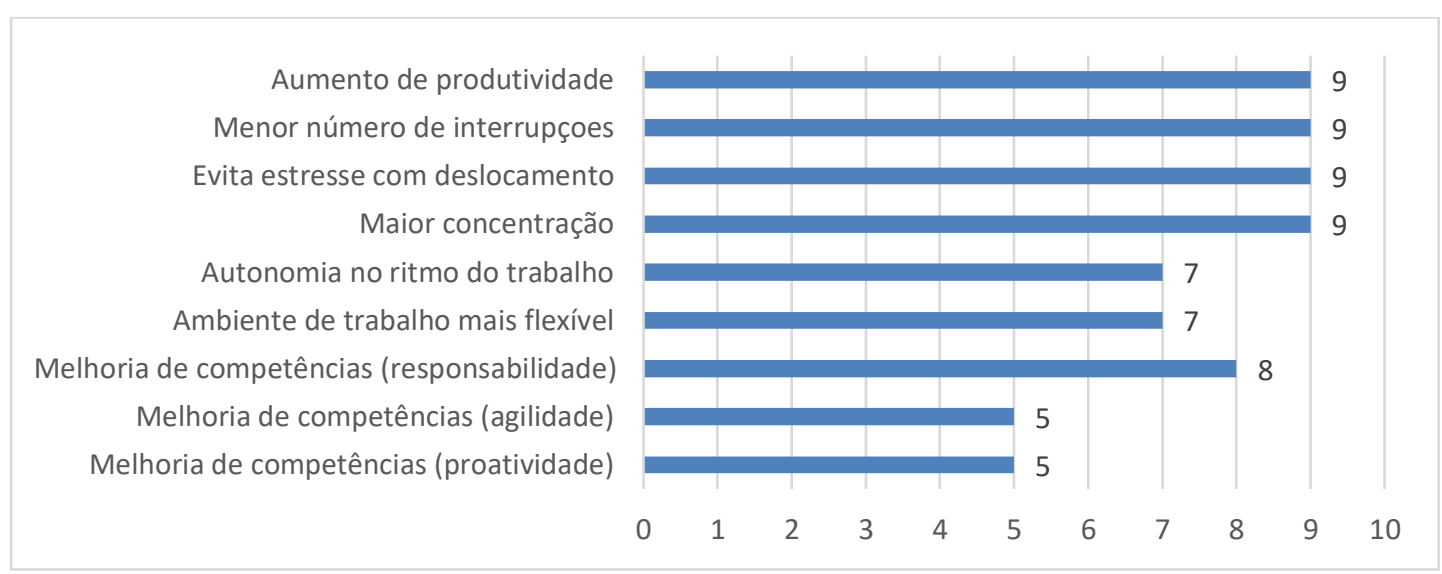

Fonte: produção própria (2019).

Em relação aos benefícios pessoais foram percebidos, principalmente, melhor utilização do tempo e economia financeira com deslocamento (HAU; TODESCAT, 2018). Ao todo, nove benefícios pessoais foram citados (Gráfico 4):

Gráfico 4 - Benefícios pessoais percebidos

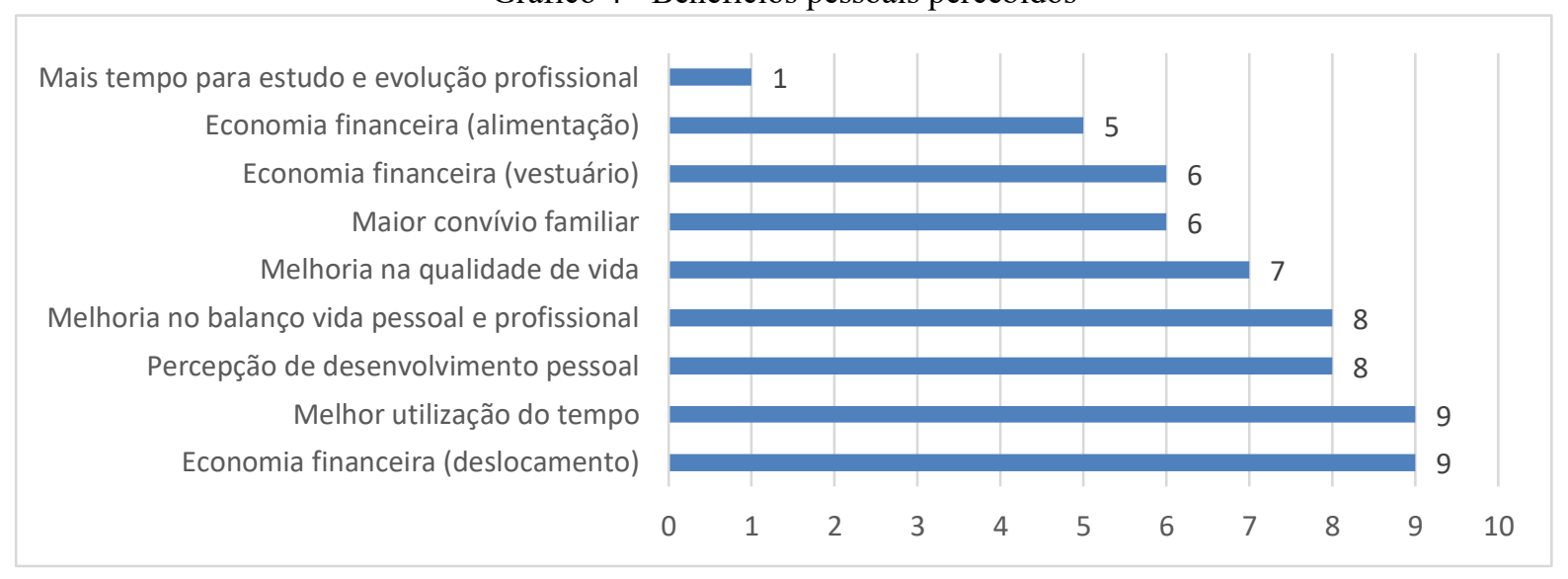

Fonte: produção própria (2019).

Percebe-se que o trabalho remoto possui a possibilidade de trazer benefícios à vida pessoal do colaborador, como também em seu desenvolvimento profissional. A gestão se beneficia com a maior facilidade na contratação de colaboradores, a disponibilidade para contato com o colaborador e a melhora na comunicação em geral. Então, melhora o recrutamento e retenção de colaboradores (LINKEDIN, 2019).

Contudo, essa modalidade de trabalho também ocasiona novos desafios aos colaboradores e à organização. Foram percebidas como principais dificuldades profissionais relacionadas ao trabalho remoto a redução da interação profissional (HAU; TODESCAT, 2018), seguida da dificuldade de participação em geração de ideias e discussões (TUNG; TURBAN, 1996) (Gráfico 5). 
Gráfico 5 - Dificuldades profissionais percebidas

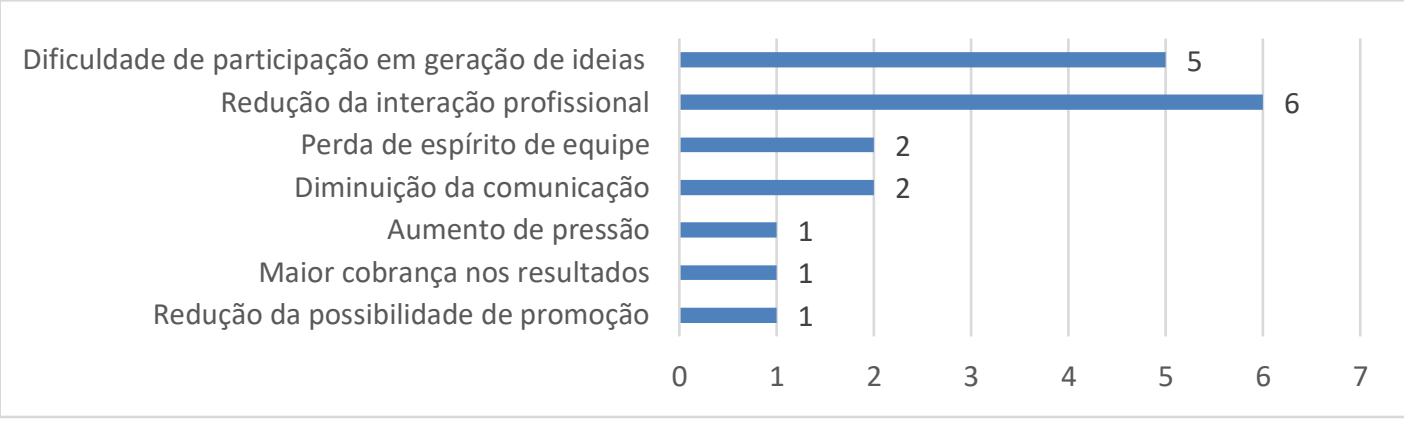

Fonte: produção própria (2019).

Foram citadas, ainda, sete dificuldades profissionais ocorridas em função do trabalho remoto, principalmente no que tange aos aspectos relacionados à interação profissional, como participação, comunicação e pertencimento na equipe. Quanto às dificuldades pessoais, a diminuição de interação pessoal e sentimento de isolamento social (HAU; TODESCAT, 2018) foram os principais destaques entre os respondentes.

Gráfico 6 - Dificuldades pessoais percebidas

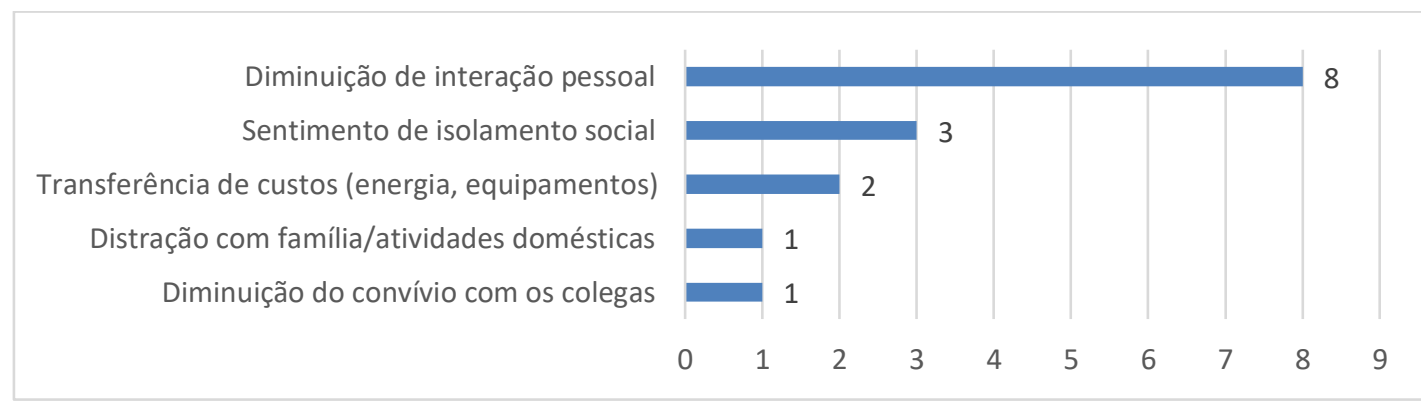

Fonte: produção própria (2019).

Destaca-se que a transferência de custos (HAU; TODESCAT, 2018) que ocorre no trabalho remoto não foi muito citada pelos respondentes. Para a gestão da empresa, corroborando com as respostas dos colaboradores, as principais dificuldades relacionadas ao desenvolvimento do trabalho remoto são a falta de interação pessoal presencial (ILLEGEMS; VERBEKE, 2004), a colaboração, a integração, o contato, a colaboração com os outros times e o convívio entre as equipes.

Por fim, os colaboradores que participaram da pesquisa citaram algumas sugestões para o desenvolvimento do trabalho remoto. Destaca-se a possibilidade de a empresa incentivar a prática de atividades esportivas, assim como melhorar a comunicação e processos que envolvam pessoas em locais físicos distintos. Torna-se importante, ainda, maximizar a proximidade dos $\mathrm{RH}$ para com os colaboradores remotos e desenvolver alguns programas para melhorar a sua inclusão.

\section{CONSIDERAÇÕES FINAIS}

Com o estudo foi possível perceber que o trabalho remoto tem ajudado a EBT no recrutamento e retenção de pessoas qualificadas considerando a concorrência no mercado. $O$ trabalho remoto é uma tendência que veio para ficar e pode ser aplicada e desenvolvida para praticamente todos os segmentos econômicos, tanto do setor privado, quanto do setor público. Para EBT, ele se mostra como o desenvolvimento natural na modernização das formas de trabalho, face a grande necessidade de flexibilidade atualmente. 
Observa-se que as EBTs, por utilizarem tecnologia de ponta e metodologias ágeis tornam o trabalho remoto uma modalidade de trabalho normal em seu meio.

A pesquisa identificou o perfil dos respondentes, suas motivações personalidade e a modalidade de trabalho remoto exercida na empresa (caracterizada por home office e trabalho realizado durante os dias úteis). E ainda, analisou-se o modo como o trabalho remoto funciona na organização no que se refere a controle de resultados, informações sobre a modalidade e comunicação.

Os resultados deste estudo podem ser utilizados como base para outras empresas que desejam implantar a modalidade de trabalho remoto, especialmente as EBTs, por se referirem a um segmento específico e que tem enfrentado dificuldades semelhantes no que se refere a contratação de trabalhadores qualificados. Sugere-se para essas empresas, alguns pontos que devem ser verificados e analisados em relação a disponibilização do trabalho remoto aos seus colaboradores. A seguir: (i) Gerar orientações e manter os colaboradores atualizados sobre elas no que tange à segurança da informação, local de trabalho ergonômico, segurança do trabalho e saúde no trabalho; (ii) Manter a Gestão de Pessoas próxima ao colaborador remoto a fim de sanar quaisquer dúvidas e auxiliar em quaisquer situações, inclusive fornecer treinamentos referentes ao trabalho remoto e apoio psicológico; (iii) Acompanhar periodicamente a experiência do colaborador nessa modalidade laboral com o intuito de promover constantes melhorias; (iv) Verificar se os mecanismos de comunicação são suficientes e utilizados; (v) Verificar se as formas de controle de resultados e trabalho são objetivas e suficientes; (vi) Impacto na satisfação profissional, qualidade de vida e comprometimento do colaborador; (vii) Impacto na qualidade do trabalho realizado; (viii) Auferir nível de isolamento do colaborador remoto e disponibilizar atividades de integração.

Ademais, foi possível perceber que o funcionamento do trabalho remoto na EBT não se diferencia em grande escala do que acontece em outros tipos de organizações, inclusive públicas. Enfatiza-se a flexibilidade e confiança depositada no trabalhador remoto, o que não ocorre em todas as organizações (SOLís, 2017). Ainda, percebe-se melhorias de sensações sentidas pelos teletrabalhadores remotos após o ingresso a essa modalidade laboral (SILVA, 2004). Frisa-se que os participantes da pesquisa são todos do sexo masculino e com nível superior de escolaridade.

O trabalho remoto envolve múltiplos atores organizacionais e possui muitas peculiaridades a serem definidas e desenvolvidas. Acredita-se que esta análise tenha sido útil para empresas de base tecnológica que possuem colaboradores em trabalho remoto ou pretendem ter, no sentido de apresentar que com as mais diversas vantagens agregadas a essa forma laboral, estão atrelados inúmeros desafios à organização e aos colaboradores.

\section{REFERÊNCIAS}

ABDULLAH, H.; ISMAIL, N. Quality of work and life balance in teleworking. International Business Management, v. 6, n. 2, p. 119-130, 2012.

ADERALDO, I. L.; ADERALDO, C. V. L.; LIMA, A. C. Aspectos críticos do teletrabalho em uma companhia multinacional. Cadernos EBAPE. BR, v. 15, n. 3, p. 511-533, 2017.

AGUILERA, A. et al. Home-based telework in France: Characteristics, barriers and perspectives. Transportation Research Part A: Policy and Practice, v. 92, p. 1-11, 2016.

BARDIN, L. Análise de Conteúdo. 4. ed. Lisboa: Rev. Atual, 2004.

BBC NEWS. Brazil's bid for tech-powered economy. United Kingdom, 2 de outubro. 2009. Disponível em: http://news.bbc.co.uk/2/hi/programmes/click_online/8284704.stm. Acesso em: 19 jan. 2019.

BRASIL. Lei No 13.467, de 13 de Julho de 2017. Altera a Consolidação das Leis do Trabalho (CLT), aprovada pelo Decreto-Lei no 5.452, de 10 de maio de 1943, e as Leis nos 6.019, de 3 de janeiro de 
1974, 8.036, de 11 de maio de 1990, e 8.212, de 24 de julho de 1991, a fim de adequar a legislação às novas relações de trabalho. Brasília, 2017. Disponível em:

http://www.planalto.gov.br/ccivil_03/_ato2015-2018/2017/lei//13467.htm. Acesso em: 09 jun. 2019.

COLLINS, A. M.; HISLOP, D.; CARTWRIGHT, S. Social support in the workplace between teleworkers, office-based colleagues and supervisors. New Technology, Work and Employment, v. 31, n. 2, p. 161-175, 2016.

CÔRTES, M. R., et al. Cooperação em empresas de base tecnológica: uma primeira avaliação baseada numa pesquisa abrangente. São Paulo em Perspectiva, v. 19, n. 1, p. 85-94, 2005.

DELLOITE. Human Capital Trends. 2018. Disponível em: https://www2.deloitte.com/content/dam/Deloitte/at/Documents/human-capital/at-2018-deloittehuman-capital-trends.pdf. Acesso em: 20 nov. 2019.

DUTCHER, E. G. The effects of telecommuting on productivity: An experimental examination. The role of dull and creative tasks. Journal of Economic Behavior \& Organization, v. 84, n. 1, p. 355363, 2012.

DUXBURY, L.; NEUFELD, D. An empirical evaluation of the impacts of telecommuting on intraorganizational communication. Journal of Engineering and Technology Management, v. 16, n. 1, p. 1-28, 1999.

GROEN, B. A. C. et al. Managing flexible work arrangements: Teleworking and output controls. European Management Journal, v. 36, n. 6, p. 727-735, 2018.

HAU, F.; TODESCAT, M. O teletrabalho na percepção dos teletrabalhadores e seus gestores: vantagens e desvantagens em um estudo de caso. Navus, v. 8, n. 3, p. 37-52, 2018.

HAZAN, Bruno Ferraz; MORATO, Amanda Duarte Pereira. Teleworking in brazilian law: grounds, perspectives and changes promoted by labor reform. Lex Humana, v. 10, n. 1, p. 1-24, 2018.

HILL, E. J.; FERRIS, M.; MÄRTINSON, V. Does it matter where you work? A comparison of how three work venues (traditional office, virtual office, and home office) influence aspects of work and personal/family life. Journal of Vocational Behavior, v. 63, n. 2, p. 220-241, 2003.

ILLEGEMS, V.; VERBEKE, A. Telework: what does it mean for management?. Long Range Planning, v. 37, n. 4, p. 319-334, 2004.

ILLEGEMS, V.; VERBEKE, A.; S'JEGERS, R. The organizational context of teleworking implementation. Technological forecasting and social change, v. 68, n. 3, p. 275-291, 2001.

KATZ, A. I. The management, control, and evaluation of a telecommuting project: A case study. Information \& Management, v. 13, n. 4, p. 179-190, 1987.

LEITE, Ana Luiza; LEMOS, Dannyela da Cunha; SCHNEIDER, Wilnei Aldir. Teletrabalho: uma revisão integrativa da literatura internacional. Contextus: Revista Contemporânea de Economia e Gestão, v. 17, n. 3, p. 187-210, set./dez. 2019.

LINKEDIN. Global Talent Trends. 2019. Disponível em: https://business.linkedin.com/talentsolutions/blog/trends-and-research/2019/global-recruiting-trends-2019. Acesso em: 20 jul. 2019. 
MARUYAMA, T.; HOPKINSON, P. G.; JAMES, P. W. A multivariate analysis of work-life balance outcomes from a large-scale telework programme. New Technology, Work and Employment, $v$. 24, n. 1, p. 76-88, 2009.

MELO, Paulo et al. Innovation Performance in Brazil-What is Missing? From the Perspective of Micro and Small Technology-Based Firms. Journal on Innovation and Sustainability, v. 6, n. 2, p. 73-96, 2015.

MROSS, Henry. Implantação de projeto-piloto de teletrabalho na Coordenação-Geral de Informática da Secretaria da Previdência. 2016. Trabalho de Conclusão de Curso (Especialização em Administração Pública) - Escola Nacional de Administração Pública, Brasília, 2016.

NILLES, J. M. Traffic reduction by telecommuting: A status review and selected bibliography. Transportation Research Part A: General, v. 22, n. 4, p. 301-317, 1988.

NOGUEIRA, A. M.; PATINI, A. C. Trabalho remoto e desafios dos gestores. Revista de Administração e Inovação, São Paulo, v. 9, n. 4, p. 121-152, 2012.

PESCIO, H. G.; PETRASIC, V. A. The role of knowledge-based firms (KBF) and technology-based firms (TBF) for innovation. Revista Gestión de las Personas y Tecnología, v. 9, n. 27, p. 65-80, 2016.

PINTO, J. O.Avaliação da viabilidade de implantação do teletrabalho no domicílio: um estudo de caso no SERPRO. 2003. Dissertação (Mestrado em Engenharia de Produção) - Universidade Federal de Santa Catarina, Florianópolis, 2003.

PREFEITURA MUNICIPAL DE FLORIANÓPOLIS (PMF). Secretaria municipal de turismo, tecnologia e desenvolvimento econômico, Polo Tecnológico. Florianópolis. Disponível em: http://www.pmf.sc.gov.br/entidades/turismo/index.php?cms=polo+tecnologico\&menu=10\&subm enuid=1733. Acesso em: 19 jan. 2020

ROCHA, C. T. M.; AMADOR, F. S. O teletrabalho: conceituação e questões para análise. Cadernos EBAPE. BR, v. 16, n. 1, p. 152-162, 2018.

ROSENFIELD, C. L.; ALVES, D. A. Autonomy and information work: telework. Dados, v. 54, n. 1, p. 207-233, 2011.

SILVA, R. T. 0 teletrabalho e suas influências na qualidade de vida no trabalho. 2004. Dissertação (Mestrado em Administração) - Universidade de São Paulo, São Paulo, 2004.

SILVA, J. A. Flexibilidad y teletrabajo: un estudio bibliométrico sobre la producción científica. Perspectivas em Ciência da Informação, v. 19, n. 2, p. 159-173, 2014.

SOLÍS, M. Moderators of telework effects on the work-family conflict and on worker performance. European Journal of Management and Business Economics, v. 26, n. 1, p. 21-34, 2017.

SULLIVAN, C.; LEWIS, S. Home-based telework, gender, and the synchronization of work and family: perspectives of teleworkers and their co-residents. Gender, Work \& Organization, v. 8, n. 2, p. 123145, 2001.

TREMBLAY, D. Organização e satisfação no contexto do teletrabalho. Revista de Administração de Empresas, v. 42, n. 3, p. 54-65, 2002. 
TREMBLAY, D.; THOMSIN, L. Telework and mobile working: analysis of its benefits and drawbacks. International Journal of Work Innovation, v. 1, n. 1, p. 100-113, 2012.

TUNG, L.-L.; TURBAN, E. Information technology as an enabler of telecommuting. International Journal of Information Management, v. 16, n. 2, p. 103-117, 1996. 